\title{
Instrumental Study of the Health Status of Picea abies [L.] Karst and Pinus mugo (Turra) and Their Relation to Environmental Parameters in the Eastern Alps
}

\author{
Dominika Falvai ${ }^{1}$, Dénes Saláta ${ }^{1, *}$, Tivadar Baltazár ${ }^{2}$ [ and Szilárd Czóbel ${ }^{1}$ \\ 1 Department of Nature Conservation and Landscape Management, Hungarian University of Agriculture and \\ Life Sciences, Páter Károly Street 1, H-2100 Gödöllő, Hungary; domi.falvai@gmail.com (D.F.); \\ czobel.szilard@uni-mate.hu (S.C.) \\ 2 Department of Agrochemistry, Soil Science, Microbiology and Plant Nutrition, Faculty of AgriSciences, \\ Mendel University in Brno, Zemědělská 1/1665, 61300 Brno, Czech Republic; baltazartivadar@gmail.com \\ * Correspondence: salata.denes@uni-mate.hu
}

Citation: Falvai, D.; Saláta, D.; Baltazár, T.; Czóbel, S. Instrumental Study of the Health Status of Picea abies [L.] Karst and Pinus mugo (Turra) and Their Relation to Environmental Parameters in the Eastern Alps. Forests 2021, 12, 716. https:/ / doi.org/10.3390/f12060716

Academic Editor: Michael Sprintsin

Received: 25 April 2021

Accepted: 22 May 2021

Published: 31 May 2021

Publisher's Note: MDPI stays neutral with regard to jurisdictional claims in published maps and institutional affiliations.

Copyright: (c) 2021 by the authors. Licensee MDPI, Basel, Switzerland. This article is an open access article distributed under the terms and conditions of the Creative Commons Attribution (CC BY) license (https:// creativecommons.org/licenses/by/ $4.0 /)$.

\begin{abstract}
Many climatic models predict significant temperature rises in mountainous regions, which may influence the distribution of montane species. Thermophilization observed or predicted in mountainous areas to date may accelerate the shift of forest-forming trees to higher areas. Our aim was to detect how the health status of Norway spruce (Picea abies [L.] Karst) and dwarf mountain pine (Pinus mugo (Turra)) changes along an altitudinal transect, and to what extent the health status of trees depends on the studied environmental variables. Field measurements were performed in the Alps with an acoustic tomograph, which is able to determine the extent and exact location of rotten parts without damage. In the case of P. abies, the stands are currently considered to be the healthiest between 1000 and $1500 \mathrm{~m}$, while they show the greatest deterioration near the lower limit of their distribution. At the lower limit of the vertical distribution of the species, a retreat of $50-100 \mathrm{~m}$ is expected. We observed a different trend in the relationship between deterioration values and altitude depending on the extent of the P. mugo belt. It seems the extent and speed of the upper movement may be different in different mountains, depending on environmental parameters.
\end{abstract}

Keywords: decay; health status; Norway spruce; Dwarf mountain pine; abiotic factors; Central Europe

\section{Introduction}

Global warming has been measured to date to affect mountain ecosystems to a greater extent than lower-lying regions [1]. Based on climate measurements in this century, the rate of temperature increase in mountainous areas is two to three times higher than in the 20th century [2,3]. In addition, there is increasing evidence that the rate of warming increases with vertical height. Differences in altitude-dependent rates of uplift in different altitude regions accelerate the rate of change in ecosystems to varying degrees [4]. Warming is also likely to affect the biodiversity and ecosystem services of mountain forests [5]. The former can lead to the disappearance of some species and changes in the composition of associations [2].

Since 1951, the vegetation period has been extended by an average of 2.7 days per decade [6,7], allowing plants to spread in ever-higher areas [8]. As tree settlement and growth are limited by low temperatures [9], warming is expected to push forests upward, leading to alpine tree boundaries and the spread of many species $[5,10,11]$. In parallel, strong stress-induced stress selection at the lower (drought) range of tree species may lead to a decrease in genetic diversity and stability. However, the impact of climate change on the future growth and health of trees in European forests is still unclear [12]. In northwestern Canada, research at the altitude tree boundary has shown that an average 
temperature of $11.3^{\circ} \mathrm{C}$ in July-August is optimal for tree growth. If the average value of these months exceeds this threshold, the positive correlation between annual tree-ring width and temperature weakens and the annual tree-ring thickness decreases [13]. Another study using a 230-year-old den-chronological data set found that both higher summer temperatures and less snowfall have a positive effect on the growth of trees growing at the tree border [14].

An analysis of the rotting of sessile oak (Quercus petraea [Matt.] Liebl.) stands of different ages in the Central European low mountain region showed that the stands in the subatlantic area are the healthiest [15]. The most degraded stands occurred in continental areas with drier climates, where the average value of species rot in the 60-year-old age group was $4.24 \%$ [15]. In the Czech Republic, a nationwide representative survey found drying in $61.2 \%$ of planted spruce (Picea abies [L.] Karst) stands, while $42.9 \%$ of visually healthy individuals were infected by a wood-rotting fungi (Armillaria ostoyae [Romagnesi] Herink), presumably due to dehydration and declining groundwater levels [16].

The correlation of $P$. abies health status with altitude was mostly examined by dendrochronological analyzes. Research in the High Tatras along an altitude gradient (839-1468 m) has shown that between the radial annual tree-ring thickness of a given year and the average temperature in March, April, June and July and the previous year in October a positive correlation is observed [17]. Trees growing in higher areas proved to be more sensitive to temperature change. A pan-European analysis confirmed that in mixed mountain forests, which represent the lower limit of the vertical distribution of $P$. abies, the production of the species has decreased significantly, by almost a quarter, over the past 30 years [18]. It has also been shown by European-scale modeling that future climatic changes can be expected to shift the distribution of spruce to higher mountainous regions [19]. The resistance of $P$. abies to climate change lags behind, for example, common beech and sessile oak, as indicated by the decline in production of the species in warmer and drier habitats [20].

In the Swiss Alps, the annual tree-ring study of nearly 600 tree individuals showed that in the case of $P$. abies, there is a strong, positive correlation between annual tree-ring thickening and the temperature during the short summer period. Modeled at higher altitudes and over a longer time scale, the production of both P. abies and Pinus mugo (Turra) showed stronger temperature dependence [21]. In the case of $P$. mugo, health studies to date have focused on the relationship between species and air pollution, as the species is an excellent bioindicator. The growth of P. abies stands in the Central European mountainous regions is also affected by air pollution-depending on sky conditions [22]. A positive correlation was observed between pollen seed abortion in P. mugo and air pollution, which was most strongly observed at the upper limit of vertical distribution of the species [23]. This also indicates an increased exposure of abiotic stressors to individuals at the tree line.

The main objective of our research was to determine and compare the health status of $P$. abies and P. mugo, as dominant forest-forming tree species, in selected mountains of the Eastern Alps. Another goal was to evaluate the health status of the studied species as a function of the altitude and the studied environmental variables. Based on our results, we would like to conclude whether it is conceivable that the range of these tree species will move upward, as this could have significant ecological and conservation consequences for the habitats they dominate.

\section{Materials and Methods}

\subsection{Study Sites}

The studies were carried out in 3 different areas of the Eastern Alps in Austria. It was performed in 2019 in the Wechsel Mountains (limestone bedrock), the Hochkar Mountains (Wechsel-gneiss), part of the Ybbstal Alps, and the Stuhleck Mountains in the Fischbach Alps (Triassic carbonate, quartzite/quartz conglomerate). The selected sites were dominated by $P$. abies in the montane belt at lower altitudes and $P$. mugo in the subalpine belt (Figure 1), so these species were selected to measure health status. In all three mountains, 
measurements were made over the entire area of the P. abies and P. mugo belt along an altitudinal transect. P. abies was measured up to $800-1600 \mathrm{~m}$ in the Wechsel Mountains, 800-1550 $\mathrm{m}$ in the Hochkar Mountains, and 850-1700 $\mathrm{m}$ in the Stuhleck Mountains, while P. mugo was measured above the spruce belt, up to the upper limit of the species' zone in all three mountains (Figure 1).

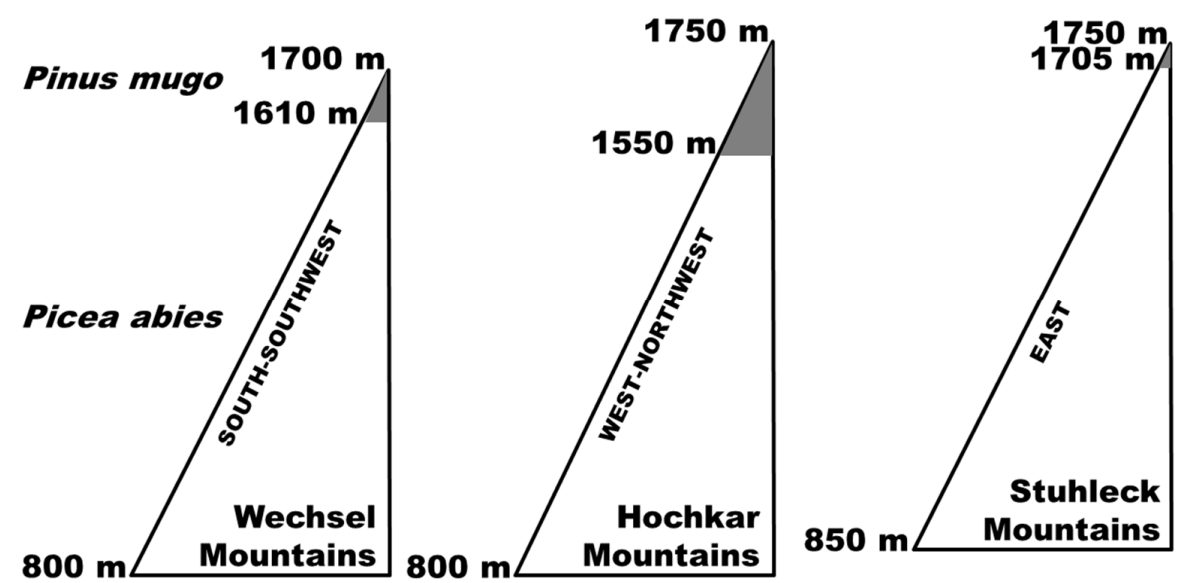

Figure 1. Vertical distribution of the examined sample areas.

\subsection{Methods}

A preliminary study was conducted in 2018 to select the altitudes for the measurements. In doing so, we measured the decay of 3 tree individuals at each altitude of $50 \mathrm{~m}$ above sea level with an acoustic tomograph, for both species. Based on the results of the preliminary study, in those altitude regions where the degree of rot was outstanding, we chose more frequent sampling in 2019. The basic consideration in selecting the tree specimens was to be at least $10 \mathrm{~m}$ away from the nearest road, and their trunk diameter and canopy should be as representative as possible of the tree specimens occurring at a given height. The health status of the trees was characterized by rot, which was measured using an acoustic tomograph (FAKOPP 3D, Sopron, Hungary). The FAKOPP instrument measures the speed of sound propagation (acoustic measurement) within the tree trunk $[24,25]$. In parallel with the fibers, the speed of sound propagation can reach $4000-5000 \mathrm{~m} / \mathrm{s}$, which is 15 times faster than the speed of air propagation. This significant difference is exploited by the instrument, as well as the fact that the speed of propagation of sound waves is closely related to the mechanical properties of the wood. This instrument is able to non-destructively detect the size and exact location of rotten or hollow regions [26] and to calculate the ratio of healthy tree trunk to total trunk for the plane of the layer above ground level (i.e., in terms of cross section). Rotting is given as a percentage, which is complementary to the proportion of the healthy part. The acoustic tomograph also calculated the wallthickness value. Acoustic tomographic measurements were performed in several vertical trunk layers, taking into account the different physiognomy of the studied species. In the case of P. abies we measured at three heights $(0.4 ; 0.8$ and $1.2 \mathrm{~m})$ from the ground level, while in the case of $P$. mugo at two heights $(0.2$ and $0.4 \mathrm{~m})$. Because acoustic tomographic measurements of sessile oak showed a significant difference between the rot of different layers of the trunk [15], we considered it necessary to perform these measurements in several layers in order to obtain more representative information of the rot of tree individuals.

\subsection{Measurements of Biotic and Abiotic Data (Environmental Parameters)}

The tree height was determined using a triangulation method and a laser altimeter (Nikon Forestry Pro, Shinagawa, Tokyo, Japan). The diameter of the trees was measured with a $5 \mathrm{~m}$ long giant tape measure (Ningbo, Yuyao, China). The soil thickness was determined with the help of the latter measuring tape and metal pipes struck with a hammer. 
Soil samples for laboratory analysis were collected in 2019. Tree samples per altitude, to examine the health of the measured trees per site, each of about $100 \mathrm{~cm}^{3}$, were taken randomly near the measured trees from the $0-10 \mathrm{~cm}$ layer. The laboratory experiment was carried out at the Department of Agrochemistry of Hungarian University of Agriculture and Life Sciences. After the mechanical preparation (sieving, chopping) and the drying of the samples, soil $\mathrm{pH}$ was measured in a 1:2.5 ratio $(w / v)$ soil: water and $1 \mathrm{M} \mathrm{KCl}$ suspension with a digital $\mathrm{pH}$ meter, Radelkis OP-211/2 [27]. Soil carbonate content was determined with a Scheibler calcimeter method [27].

\subsection{Statistical Analysis}

Statistical analysis was performed using the PAST (PAleontological STatistics Version 3.21 and 4.05) statistical software package [28-30]. For the basic statistics we used the summary statistics, two sample $t$ test and boxplot modules of the software. Based on the results of our previous research [31,32], in order to get a more nuanced picture, we characterized the health status of two species in the sample areas in the light of altitude by plotting local regression curves instead of linear regression. For this regression the software's LOESS smoothing option was used, with medium (0.5) smoothing factor. LOESS Smoothing based on the algorithm of "LOWESS" (Locally Weighted Scatterplot Smoothing) [29,33,34]. To analyze the correlation between environmental parameters, morphometric and rot data, we used the software's correlation module and linear $r$ (Pearson) correlation method.

\section{Results}

\subsection{Picea Abies}

For all three mountains, the decay data differ significantly by species on different locations (Figure 2, Table 1, for average decay W-PA vs. W-PM uneq. var. $t=26.59$ $p<0.001$, H-PA vs. H-PM uneq. var. $\mathrm{t}=16.14 p<0.001$, S-PA vs. S-PM uneq. var. $\mathrm{t}=11.59$ $p<0.001)$. The largest significant difference was detected in the Wechsel Mountains, while the smallest was detected in the Stuhleck Mountains. The extent of interquartilis in the Wechsel Mountains was found to be the smallest, while in the case of Hochkar it was found to be the largest, with significant upper quartilis in the latter. For each object, the highest average deterioration was at the measured height closest to ground level $(40 \mathrm{~cm})$, and at higher levels, the deterioration value decreased.

For the $P$. abies stand in the Wechsel Mountains, the percentage of rot was higher between 800 and $1000 \mathrm{~m}$ and between 1500 and $1600 \mathrm{~m}$ above sea level than at an altitude between 1000 and $1500 \mathrm{~m}$ above sea level (Figure 3). From $1500 \mathrm{~m}$ upwards to the upper distribution limit of the tree species, the degree of rot gradually increased, as indicated by the confidence interval, but there was less damage to the trees in this altitude zone than in the lower areas. The standard deviation of the deterioration values was the highest between 800 and $1200 \mathrm{~m}$ and above $1500 \mathrm{~m}$, while the smallest standard deviation values were observed between 1250 and $1500 \mathrm{~m}$.

Table 1. Basic statistics of the studied tree species' decay data in the selected mountains at different sampling heights (W-Wechsel Mountains, H-Hochkar Mountains, S-Stuhleck Mountains, PA-Picea abies, PM-Pinus mugo).

\begin{tabular}{|c|c|c|c|c|c|c|c|c|c|c|c|c|c|c|c|}
\hline Decay & $\begin{array}{c}\text { W- } \\
\text { PA- } \\
40\end{array}$ & $\begin{array}{c}\text { W- } \\
\text { PA- } \\
80\end{array}$ & $\begin{array}{l}\text { W- } \\
\text { PA- } \\
120\end{array}$ & $\begin{array}{c}\text { W- } \\
\text { PM- } \\
20\end{array}$ & $\begin{array}{c}\text { W- } \\
\text { PM- } \\
40\end{array}$ & $\begin{array}{c}\text { H- } \\
\text { PA- } \\
40\end{array}$ & $\begin{array}{l}\text { H- } \\
\text { PA- } \\
80\end{array}$ & $\begin{array}{l}\text { H- } \\
\text { PA- } \\
120\end{array}$ & $\begin{array}{c}\text { H- } \\
\text { PM- } \\
20\end{array}$ & $\begin{array}{c}\text { H- } \\
\text { PM- } \\
40\end{array}$ & $\begin{array}{c}\text { S-PA- } \\
40\end{array}$ & $\begin{array}{c}\text { S-PA- } \\
80\end{array}$ & $\begin{array}{c}\text { S-PA- } \\
120\end{array}$ & $\begin{array}{c}\text { S- } \\
\text { PM- } \\
20\end{array}$ & $\begin{array}{c}\text { S- } \\
\text { PM- } \\
40\end{array}$ \\
\hline $\mathrm{N}$ & 41 & 41 & 41 & 19 & 19 & 41 & 41 & 41 & 39 & 39 & 38 & 38 & 38 & 10 & 10 \\
\hline Min & 0.00 & 0.00 & 0.00 & 46.33 & 47.67 & 0.33 & 0.33 & 0.00 & 18.67 & 18.33 & 0.00 & 0.00 & 0.00 & 42.00 & 30.67 \\
\hline Max & 30.67 & 37.00 & 43.67 & 77.67 & 78.33 & 54.00 & 42.67 & 41.67 & 74.33 & 75.00 & 38.33 & 39.67 & 38.67 & 79.33 & 79.33 \\
\hline Mean & 6.81 & 6.42 & 7.42 & 63.53 & 63.74 & 14.15 & 13.22 & 10.83 & 57.59 & 57.42 & 8.64 & 7.60 & 8.03 & 60.67 & 58.13 \\
\hline Std. error & 1.07 & 1.13 & 1.40 & 1.80 & 1.87 & 2.02 & 1.86 & 1.77 & 2.09 & 2.13 & 1.52 & 1.47 & 1.44 & 3.78 & 4.63 \\
\hline Variance & 47.10 & 52.56 & 80.31 & 61.90 & 66.60 & 166.73 & 141.82 & 128.88 & 170.46 & 176.43 & 88.35 & 82.44 & 78.67 & 143.16 & 214.24 \\
\hline Stand. dev & 6.86 & 7.25 & 8.96 & 7.87 & 8.16 & 12.91 & 11.91 & 11.35 & 13.06 & 13.28 & 9.40 & 9.08 & 8.87 & 11.96 & 14.64 \\
\hline Median & 5.33 & 4.33 & 4.33 & 64.00 & 65.00 & 9.33 & 8.67 & 7.33 & 60.67 & 60.33 & 4.84 & 4.17 & 4.67 & 60.33 & 58.84 \\
\hline 25 prcntil & 3.00 & 1.50 & 2.33 & 61.33 & 61.67 & 4.00 & 3.67 & 2.67 & 51.33 & 48.67 & 2.50 & 1.67 & 2.00 & 52.25 & 47.92 \\
\hline 75 prcntil & 8.33 & 9.50 & 9.00 & 69.00 & 69.33 & 22.33 & 21.17 & 16.00 & 67.00 & 68.33 & 14.33 & 12.08 & 13.08 & 67.33 & 67.25 \\
\hline
\end{tabular}




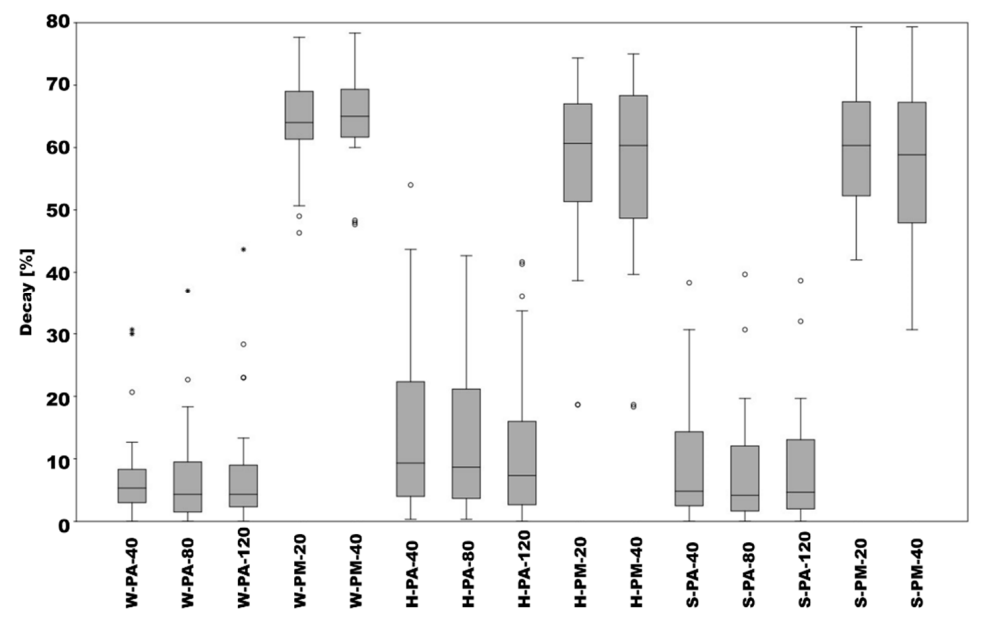

Figure 2. Decay of the studied tree species in the selected mountains at different sampling heights (W-Wechsel Mountains, H-Hochkar Mountains, S-Stuhleck Mountains, PA-Picea abies, PM-Pinus mugo).
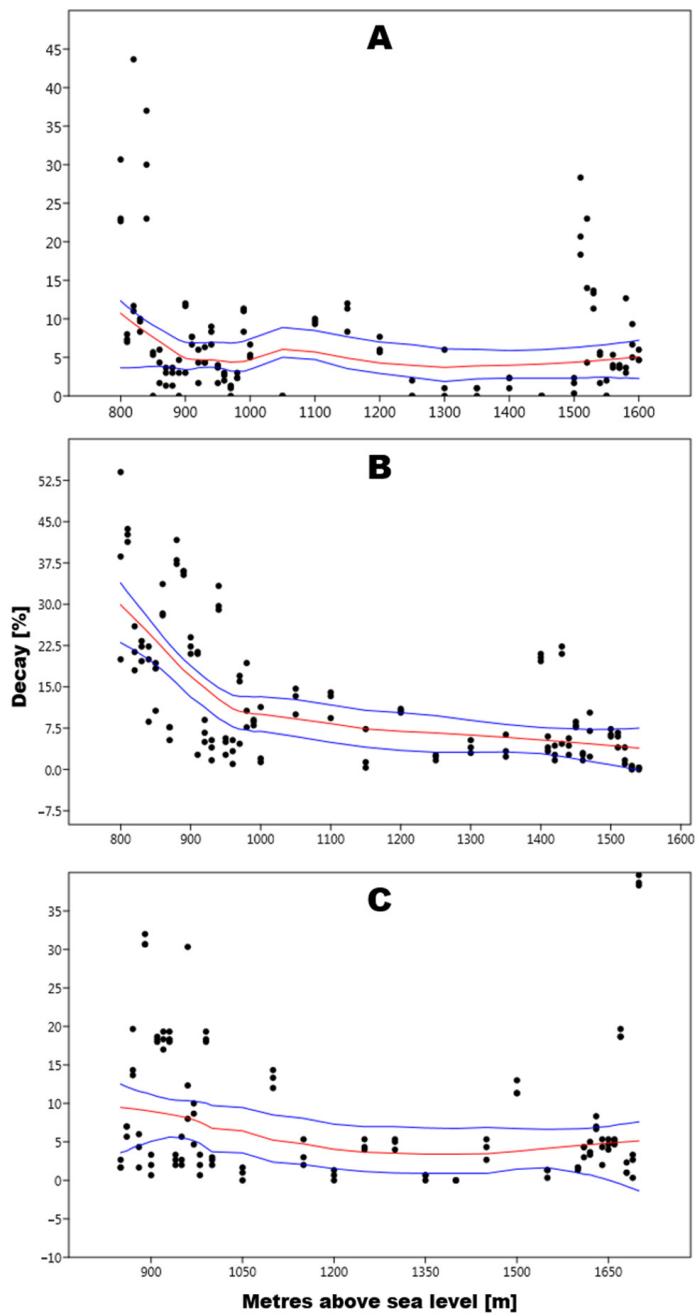

Figure 3. Changes in the decay of the Picea abies stand in the studied mountains ((A)-Wechsel Mountains, (B)-Hochkar Mountains, (C)-Stuhleck Mountains) in light of the altitude. Dots represent average decay of three sampled individual trees at same sampling height at every examined elevation. In the figures, in addition to the trend lines (local regression, red lines), the bootstrap is also shown (blue lines)-bootstrap option estimates the 95\% confidence band [29]. 
In the Hochkar Mountains, the deterioration of P. abies trees shows a clear decreasing trend with increasing height (Figure 3). The highest rot values of the species can be observed with a decreasing trend between 800 and $1100 \mathrm{~m}$, and with an increasing trend between 1400 and $1500 \mathrm{~m}$. The most moderate variances are between 1100 and $1400 \mathrm{~m}$ and above $1500 \mathrm{~m}$.

Similar to the previous two study sites, Stuhleck had both the lowest deterioration values and standard deviations in the mean altitude range between 1050 and $1550 \mathrm{~m}$. The highest deterioration was measured between 850 and $1050 \mathrm{~m}$, with a decreasing trend; however, it should be noted that the deterioration values increased again from $1650 \mathrm{~m}$ (Figure 3).

\subsection{Pinus Mugo}

The median as well as the upper quartile values proved to be the highest in the Wechsel Mountains (Figure 2, Table 1). For all three mountains, the median values varied in a very small range at the measurement heights examined from ground level. The Stuhleck Mountains have the lowest median value. The interquartile extent was larger in the Stuhleck and Hochkar mountains compared to the Wechsel stand and moved in a similar range.

Based on the local regression in the Wechsel Mountains, it can be concluded that the degree of rot of the P. mugo increased towards higher altitudes (Figure 4). At the height of $1610 \mathrm{~m}$ the degree of rot was clearly lowest. The degree of rot increased significantly at the lower limit of the distribution of the species, between 1610 and $1640 \mathrm{~m}$. At higher altitudes, the measured values were in almost the same range, with another slight increase from $1670 \mathrm{~m}$ up to the upper limit of the species' distribution.
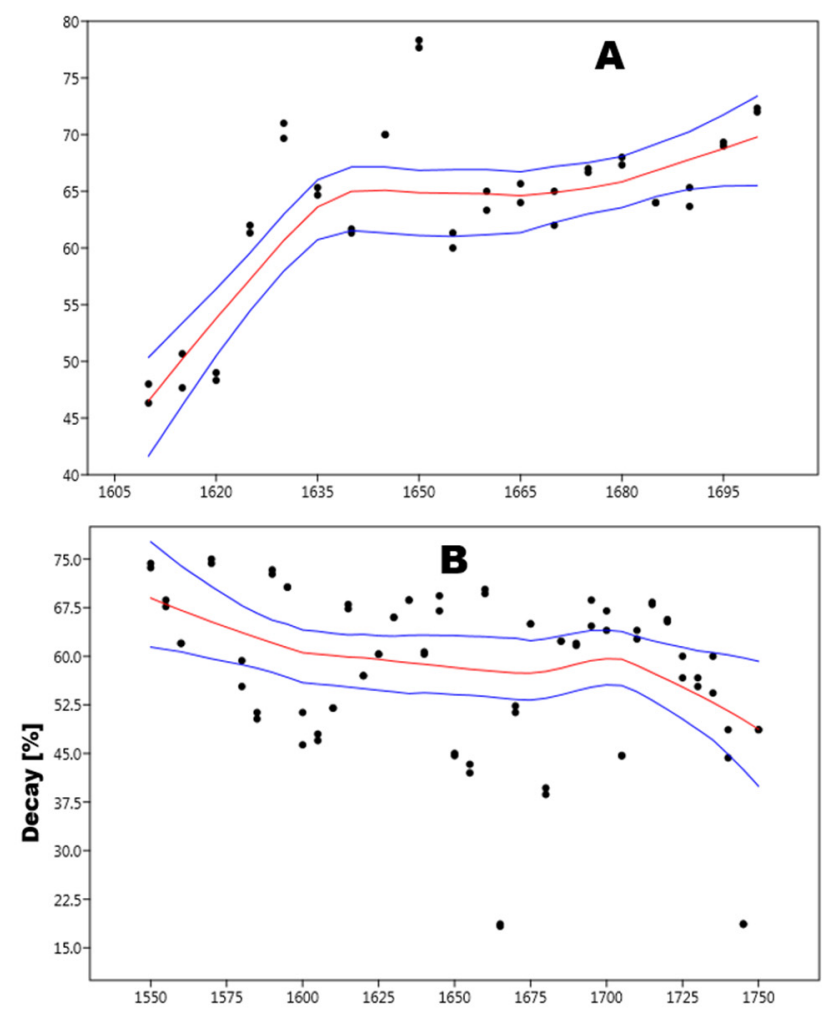

Figure 4. Cont. 


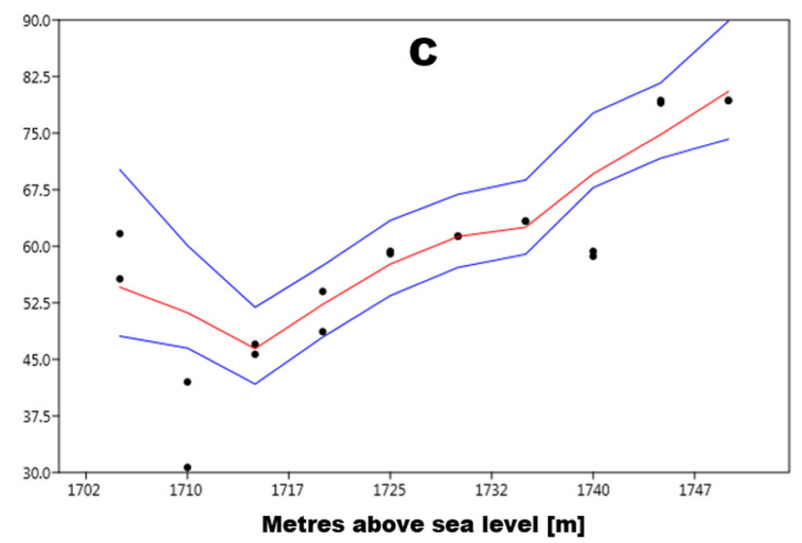

Figure 4. Changes in the decay of the Pinus mugo stand in the studied mountains ((A)-Wechsel Mountains, (B)-Hochkar Mountains, (C)-Stuhleck Mountains) in the light of the altitude. Dots represent average decay of three sampled individual trees at the same sampling height at every examined elevation. In the figures, in addition to the trend lines (local regression, red lines), the bootstrap is also shown (blue lines)-bootstrap option estimates the $95 \%$ confidence band [29].

In the case of the Hochkar Mountains, the deterioration of the P. mugo typically decreases with increasing altitude, as can be seen along the trend line (Figure 4). Deterioration values are highest between 1550 and $1600 \mathrm{~m}$, while the average is lowest between 1730 and $1750 \mathrm{~m}$. The degree of decay decreases relatively evenly between 1600 and $1700 \mathrm{~m}$, and then shows a steeper decreasing image above $1700 \mathrm{~m}$.

In the case of Stuhleck Mountains, the rotting of the examined stand shows a steeply decreasing trend from $1700 \mathrm{~m}$ to an altitude of $1715 \mathrm{~m}$; however, from this height there is a steeply increasing trend up to the tree boundary.

\subsection{Environmental Parameters}

In the case of the Wechsel Mountains, we found a positive linear relationship between the following parameters: MASL (Metres Above Sea Level) vs. Diameter $(\mathrm{r}=0.76, p<0.01$ ), Decay vs. $\mathrm{pH}$ Water $(\mathrm{r}=0.69, p<0.01)$, Decay vs. $\mathrm{pH} \mathrm{KCl}(\mathrm{r}=0.59, p<0.05)$, Diameter vs. Slope $(r=0.56, p<0.05)$, and Tree height vs. Soil thickness $(r=0.54, p<0.05)$ (Figure 5$)$. In contrast, Decay vs. Wallthickness $(\mathrm{r}=-0.91, p<0.001)$, Diameter vs. $\mathrm{pH}$ Water $(\mathrm{r}=-0.55$, $p<0.05)$, and Wallthickness vs. $\mathrm{pH}$ Water $(\mathrm{r}=-0.61, p<0.05)$ showed a negative correlation (Figure 5).

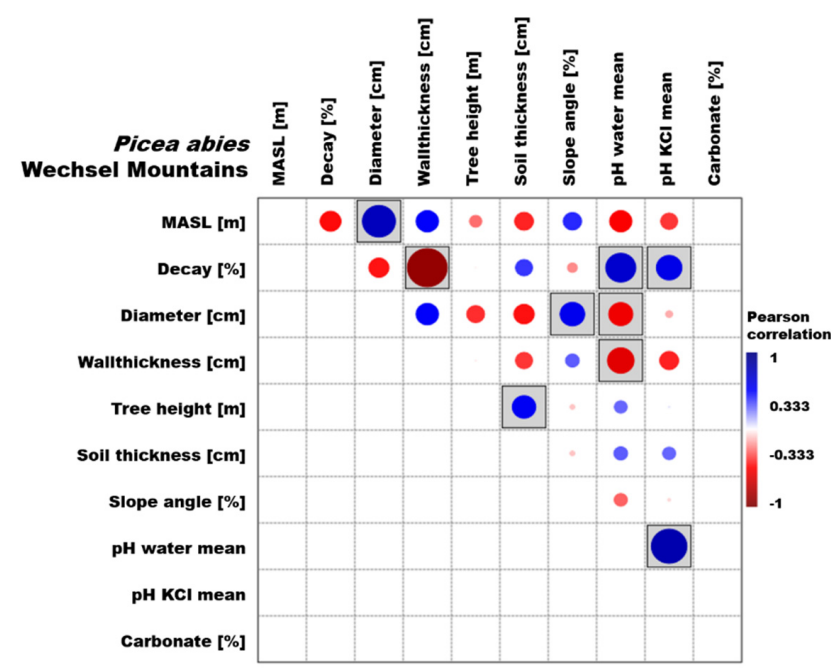

Figure 5. Investigation of linear (Pearson) correlation of environmental parameters, morphometric and rot data measured in the Picea abies stand of the Wechsel Mountains (MASL-metres above sea level, blue-positive, red-negative correlation, boxed- $p<0.05$ significance). 
In the case of the Hochkar Mountains, we found a positive linear relationship between the Soil thickness vs. Slope $(\mathrm{r}=0.53, p<0.05)$, while we obtained a negative correlation between Decay vs. Wallthickness $(r=-0.95, p<0.001)$ (Figure 6).

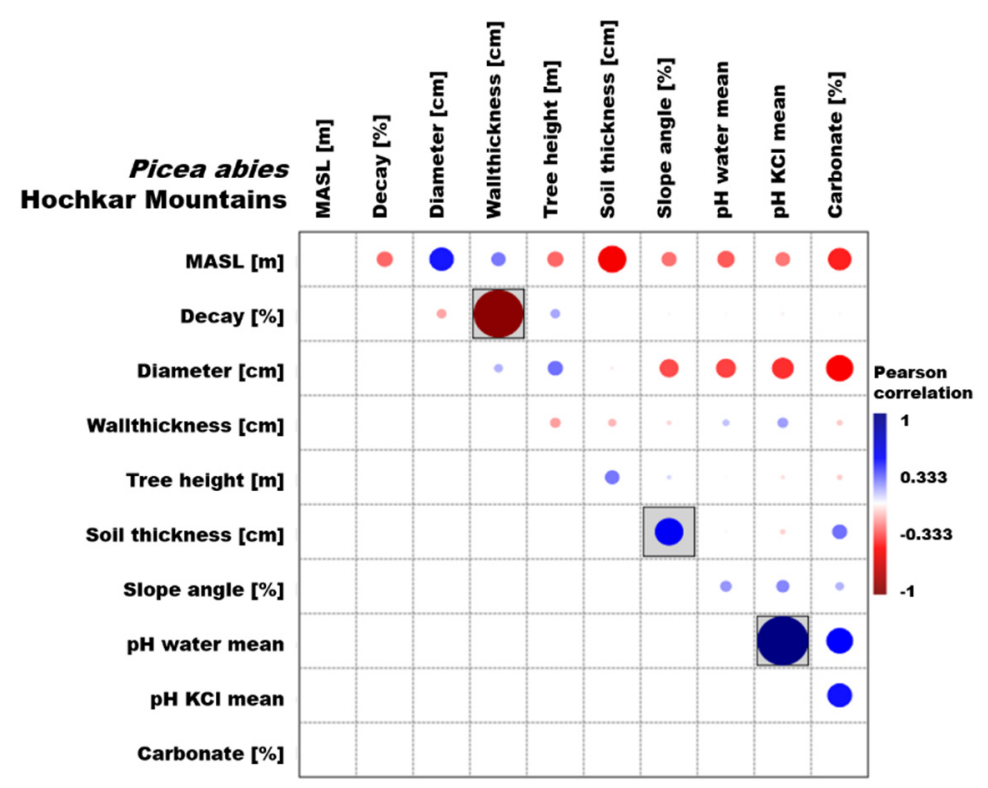

Figure 6. Investigation of linear (Pearson) correlation of environmental parameters, morphometric and rot data measured in the Picea abies stand of the Hochkar Mountains (MASL-metres above sea level, blue-positive, red-negative correlation, boxed- $p<0.05$ significance).

In the case of the Stuhleck Mountains, we found a positive linear relationship between the following parameters: MASL vs. Slope $(r=0.74, p<0.001)$, and Diameter vs. Tree height $(r=0.88, p<0.001)$ (Figure 7). In contrast, there was a negative correlation between Elevation vs. Soil thickness $(\mathrm{r}=-0.84, p<0.001)$, Soil thickness vs. Slope $(\mathrm{r}=-0.73$, $p<0.01)$, and Decay vs. Wallthickness $(r=-0.92, p<0.001)$ (Figure 7).

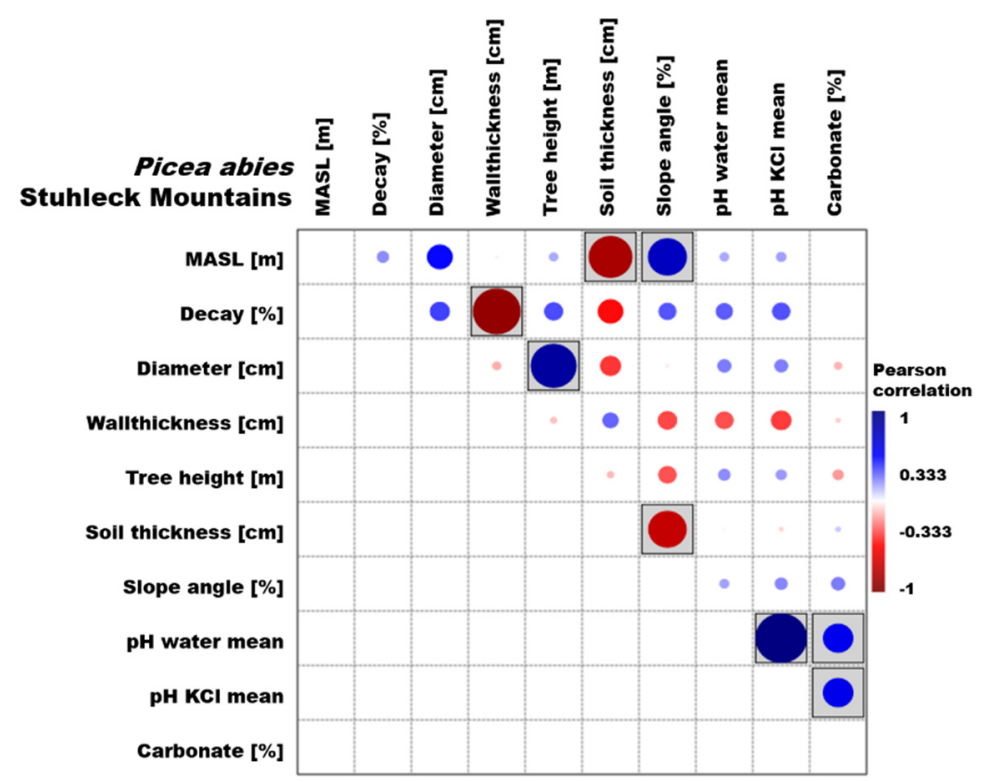

Figure 7. Investigation of linear (Pearson) correlation of environmental parameters, morphometric and rot data measured in the Picea abies stand of the Stuhleck Mountains (MASL-metres above sea level, blue-positive, red negative-correlation, boxed- $p<0.05$ significance). 


\section{Discussion}

\subsection{Picea Abies}

Based on acoustic tomography data, the Wechsel P. abies stand appears to be the healthiest, while the Hochkar appears to be in the least good health. The rotting results show that the health status of individuals is at its worst at the lower altitude distribution limit of the species. The latter is in harmony with Krejza et al. [35] findings, based on stem diameter analysis along an elevation gradient, that current climatic conditions in the Central European region are not suitable for growing P. abies at lower elevations, and also consistent with the observations of Hilmers et al. [18] for modelling approach. Based on rot measurements, P. abies appears to be in the best health at 1000-1100 to 1400-1500 m above sea level under current climatic conditions, which is also considered to be the optimum distribution of the species in the studied mountains. In this range, the values of rot were similar to the data of Quercus petraea stands of different ages in the Carpathian Basin $[15,26]$. The significant variance in the significantly higher rot values observed at the lower distribution limit indicates that the lower region of the distribution area of the species is less favorable for the species, so it is conceivable that the lower occurrence limit will move upwards, as can be seen in the case of the Hochkar Mountains (Figure 3). Based on our previous studies [32], it seems that although it would be more favorable for P. abies to move to higher areas in terms of fungal infestation, it however rots more in several mountains near the upper altitude limit of the tree species, presumably due to increasing stress. The latter may inhibit the upward movement of the species, such that even a narrowing of the distribution may occur in the case of $P$. abies as the lower distribution limit moves upwards. The latter would be unfavorable from a nature conservation point of view, as it would be accompanied by a narrowing of the species' dominant habitat. Presumably, only a subset of species associated with P. abies could adapt to this area narrowing, which in the long term could lead to a decrease in habitat species diversity, similar to that seen with declining alpine grassland extent [36,37].

\subsection{Pinus Mugo}

There is no clear trend between the deterioration of different height levels measured from the ground level. Based on the median values, the Stuhleck Mountains proved to be the healthiest, while the Wechsel Mountains was the least healthy due to the higher median and high interquartile extent. In the case of the P. mugo in the Wechsel and Stuhleck mountains, the degree of rot increased towards higher terrains. Lower rot values measured at the lower distribution limit of the species, and higher decay values measured in the upper distribution zone, may indicate that changes in the vertical range and upward movement of the species-unlike P. abies-are unlikely in the near future. The significantly higher rot values of $P$. mugo compared to P. abies can be explained by the higher abiotic stress characteristic of the higher alpine region. In contrast, in the case of the Hochkar Mountains, which have the widest vertical P. mugo belt, the rotting of the species decreases with increasing altitude of the species. It shows a close-to-stagnation in the middle range of the species.

\subsection{Environmental Parameters}

Based on the linear correlations, the Wechsel P. abies stand proved to be the most sensitive to environmental factors, where water $\mathrm{pH}$ showed a negative correlation with diameter and wallthickness, while slope showed a positive correlation with diameter and soil thickness with tree height. No such correlations were found for Hochkar and Stuhleck P. abies stands. Regarding deterioration, it should be noted that in the case of Wechsel we found a positive correlation with soil $\mathrm{pH}(\mathrm{pH} \mathrm{KCl})$. We must point out that for all the tree locations, Wechsel, Hochkar and Stuhleck, there is a very strong, negative correlation between decay and wallthickness. All other correlations named in the Results section refer to correlations between environmental parameters, so a more detailed discussion does 
not seem warranted. Nevertheless, these parameters can also have a significant effect on vegetation.

\subsection{General Discussion}

Our results are partly consistent with Lenoir et al. [8], Liang et al. [9] and Jump et al. [38] findings based on field observations, and Vittoz et al. [10], Falk and Hempelmann [19] and Bussotti et al. [11] modeling results, i.e., the current climate change may change the distribution of tree species, and the increase in temperature may cause a rapid upward shift in the range of mountain species. Higher rot values at the upper limits of the distribution of P. abies and P. mugo may also indicate that if the range of tree species shifts upwards, they will be exposed to increasing cold stress and more extreme weather events (e.g., stronger and more frequent windstorms, icebreaking), thereby leading to declining fitness.

The potential shift of mountain vegetation belts and the transformation of habitats may not be favorable from a nature conservation point of view, because it is likely that not all species are able to migrate with the stand-forming tree species.

\section{Conclusions}

In the case of P. abies, it is clear for all three mountains that the stands are the healthiest between 1000 and $1500 \mathrm{~m}$, while they show the greatest deterioration near the lower limit of their distribution. At the lower limit of the vertical distribution of the species, a retreat of 50-100 $\mathrm{m}$ is expected based on deterioration values. In contrast, the clear upward trend in the upper distribution limit is questionable, based on deterioration data. Further studies are needed to confirm the latter.

In the case of $P$. mugo, we observed a different trend in the relationship between deterioration values and altitude in the studied mountains. However, when evaluating the results, it should be taken into account that the P. mugo belt studied in the Hochkar Mountains was the widest $(200 \mathrm{~m})$, as opposed to the 100-m belt in the Wechsel Mountains and the 50-m belt in Stuhleck. Thus, in our opinion, the changes measured in the Hochkar Mountains are the most relevant for drawing general conclusions due to the greater stability and ability to self-regulate of larger monodominant stands.

The trends observed in the Hochkar Mountains clearly indicate that the altitudinal range changing of both studied species, and thus the area dominated by them, are expected to shift upwards. However, this expected trend in the future may be different in the extent and speed in different mountains of the Alps, depending on environmental parameters.

Author Contributions: Data collection D.F.; software analysis, visualization, writing D.S.; data validation, methodology T.B.; conceptualization, writing, supervision S.C. All authors have read and agreed to the published version of the manuscript.

Funding: This research received no external funding.

Data Availability Statement: The data that support the findings of this study are available on request from the corresponding author.

Acknowledgments: The research was supported by the Doctoral School of Environmental Sciences of Hungarian University of Agriculture and Life Sciences.

Conflicts of Interest: The authors declare no conflict of interest.

\section{References}

1. Fourth Assessment Report of Intergovermental Panel on Climate Change. Available online: http:/ /www.ipcc.ch (accessed on 10 April 2021).

2. Nogués-Bravo, D.; Araújo, M.B.; Errea, M.P.; Martínez-Rica, J.P. Exposure of global mountain systems to climate warming during the 21st Century. Glob. Environ. Chang. 2007, 17, 420-428. [CrossRef]

3. Wipf, S.; Stöckli, V.; Herz, K.; Rixen, C. The oldest monitoring site of the Alps revisited: Accelerated increase in plant species richness on Piz Linard summit since 1835. Plant Ecol. Divers. 2013, 6, 447-455. [CrossRef] 
4. Pepin, N.; Bradley, R.; Diaz, H. Elevation-dependent warming in mountain regions of the world. Nat. Clim. Chang. 2015, 5, 424-430. [CrossRef]

5. Máliš, F.; Kopecký, M.; Petřík, P.; Vladovič, J.; Merganič, J.; Vida, T. Life stage, not climate change, explains observed tree range shifts. Glob. Chang. Biol. 2016, 22, 1904-1914. [CrossRef] [PubMed]

6. Defila, C.; Clot, B. Phytophenological trends in the Swiss Alps, 1951-2002. Meteorol. Z. 2005, 14, 191-196. [CrossRef]

7. Le Climat Change-Que Faire? Le Nouveau Rapport des Nations Unies sur le Climat (GIEC 2007) et ses Principaux Résultats dans L'optique de la Suisse. Available online: http://proclimweb.scnat.ch/portal/ressources/854.pdf (accessed on 10 April 2021).

8. Lenoir, J.; Gegout, J.C.; Marquet, P.A.; de Ruffray PBrisse, H. A significant upward shift in plant species optimum elevation during the 20th century. Science 2008, 320, 1768-1771. [CrossRef] [PubMed]

9. Liang, E.; Wang, Y.; Piao, S.; Lu, X.; Camarero, J.J.; Zhu, H.; Zhu, L.; Ellison, A.M.; Ciais, P.; Peñuelas, J. Species interactions slow warming-induced upward shifts of treelines on the Tibetan Plateau. Proc. Natl. Acad. Sci. USA 2016, 113, 4380-4385. [CrossRef] [PubMed]

10. Vittoz, P.; Cherix, D.; Gonseth, Y.; Lubini, V.; Maggini, R.; Zbinden, N.; Zumbach, S. Climate change impacts on biodiversity in Switzerland: A review. J. Nat. Conserv. 2013, 21, 154-162. [CrossRef]

11. Bussotti, F.; Pollastrini, M.; Holland, V.; Brüggemann, W. Functional traits and adaptive capacity of European forests to climate change. Environ. Exp. Bot. 2015, 111, 91-113. [CrossRef]

12. Mátyás, C.; Kramer, K. Adaptive management of forests and their genetic resources in the face of climate change. Erdészettudományi Közlemények 2016, 6, 7-16, (In Hungarian with English Summary). [CrossRef]

13. D'Arrigo, R.D.; Kaufmann, R.K.; Davi, N.; Jacoby, G.C.; Laskowski, C.; Myneni, R.B.; Cherubini, P. Thresholds for warminginduced growth decline at elevational tree line in the Yukon Territory, Canada. Glob. Biogeochem. Cycles 2004, 18, 3021. [CrossRef]

14. Dolezal, J.; Altman, J.; Vetrova, V.P.; Hara, T. Linking two centuries of tree growth and glacier dynamics with climate changes in Kamchatka. Clim. Chang. 2014, 124, 207-220. [CrossRef]

15. Trenyik, P.; Skutai, J.; Szirmai, O.; Czóbel, S. Instrumental analysis of health status of Quercus petraea stands in the Carpathian Basin. Central Eur. For. J. 2019, 65, 34-40. [CrossRef]

16. Holuša, J.; Lubojacký, J.; Čurn, V.; Tonka, T.; Lukášová, K.; Horák, J. Combined effects of drought stress and Armillaria infection on tree mortality in Norway spruce plantations. Forest Ecol. Manag. 2018, 427, 434-445. [CrossRef]

17. Savva, Y.; Oleksyn, J.; Reich, P.B.; Tjoelker, M.G.; Vaganov, E.A.; Modrzynski, J. Interannual growth response of Norway spruce to climate along an altitudinal gradient in the Tatra Mountains, Poland. Trees 2006, 20, 735-746. [CrossRef]

18. Hilmers, T.; Avdagić, A.; Bartkowicz, L.; Bielak, K.; Binder, F.; Bončina, A.; Dobor, L.; Forrester, D.I.; Hobi, M.L.; Ibrahimspahić, A.; et al. The productivity of mixed mountain forests comprised of Fagus sylvatica, Picea abies, and Abies alba across Europe. Int. J. For. Res. 2019, 92, 512-522. [CrossRef]

19. Falk, W.; Hempelmann, N. Species Favourability Shift in Europe due to Climate Change: A Case Study for Fagus sylvatica L. and Picea abies (L.) Karst. Based on an Ensemble of Climate Models. Int. J. Climat. 2013, 2013, 787250. [CrossRef]

20. Sáenz-Romero, C.; Kremer, A.; Nagy, L.; Újvári-Jármay, É.; Ducousso, A.; Kóczán-Horváth, A.; Hansen, J.K.; Mátyás, C. Common garden comparisons confirm inherited differences in sensitivity to climate change between forest tree species. PeerJ 2019, 7, e6213. [CrossRef]

21. Matthias, J.; Bugmann, H.; Nötzli, M.; Bigler, C. Among-tree variability and feedback effects result in different growth responses to climate change at the upper treeline in the Swiss Alps. Ecol. Evol. 2017, 7, 7937-7953. [CrossRef]

22. Juráň, S.; Šigut, L.; Holub, P.; Fares, S.; Klem, K.; Grace, J.; Urban, O. Ozone flux and ozone deposition in a mountain spruce forest are modulated by sky conditions. Sci. Total Environ. 2019, 672, 296-304. [CrossRef]

23. Chropeňová, M.; Gregušková, E.K.; Karásková, P.; Přibylová, P.; Kukučka, P.; Baráková, D.; Čupr, P. Pine needles and pollen grains of Pinus mugo Turra-A biomonitoring tool in high mountain habitats identifying environmental contamination. Ecol. Indic. 2016, 66, 132-142. [CrossRef]

24. Divós, F.; Divós, P. Resolution of stress wave based Acoustic Tomography. In Proceedings of the 14th International Symposium on Nondestructive Testing of Wood; Broker, F.-W., Ed.; Shaker Verlag: Aachen, Germany, 2005; pp. 309-314.

25. Divós, F.; Dénes, L.; Iniguez, G. Effect of crosssectional change of a board specimen on stress wave velocity determination. Holzforschung 2005, 59, 230-231. [CrossRef]

26. Trenyik, P.; Ficsor, C.; Demeter, A.; Falvai, D.; Czóbel, S. Examination the health state with instrumental measurements and the diversity of sessile oak stands in Zemplén mountains. Columella 2017, 4, 21-30. [CrossRef]

27. Buzás, I. Soil and agrochemical test method book 2. Physico-chemical and chemical test methods for soils. Agrokémia Talajt. 1989, 38, 504-505. (In Hungarian)

28. Hammer, Ø. PAST-PAleontological STatictics Version 3.06 Reference Manual; Natural History Museum-University of Oslo: Oslo, Norway, 1999-2015; 225p.

29. Hammer, Ø. PAST-PAleontological STatictics Version 4.05 Reference Manual; Natural History Museum-University of Oslo: Oslo, Norway, 1999-2021; 284p.

30. Hammer, Ø.; Harper, D.A.T.; Ryan, P.D. PAST-Paleontological Statistics Software Package for Education and Data Analysis. Palaeontol. Electron. 2001, 4, 1-9.

31. Falvai, D.; Baltazár, T.; Czóbel, S. Health status analysis of Norway spruce and shrubby pine along an elevation gradient. Columella 2019, 6, 29-36. [CrossRef] 
32. Falvai, D.; Baltazár, T.; Szegleti, Z.; Czóbel, S. Investigation of the health status of Picea abies and Pinus mugo tree species in the semi-natural forest stands of the Wechsel Mountains. Természetvédelmi Közlemények 2020, 26, 16-27, (In Hungarian with English Summary). [CrossRef]

33. Cleveland, W.S. Robust locally weighted fitting and smoothing scatterplots. J. Am. Stat. Assoc. 1979, 74, 829-836. [CrossRef]

34. Cleveland, W.S. A program for smoothing scatterplots by robust locally weighted fitting. Am. Stat. 1981, 35, 54. [CrossRef]

35. Krejza, J.; Cienciala, E.; Světlík, J.; Bellan, M.; Noyer, E.; Horáček, P.; Štěpánek, P.; Marek, M.V. Evidence of climate-induced stress of Norway spruce along elevation gradient preceding the current dieback in Central Europe. Trees 2021, 35, 103-119. [CrossRef]

36. Baker, B.B.; Moseley, R.K. Advancing treeline and retreating glaciers: Implications for conservation in Yunnan, PR China. Arct. Antarct. Alp. Res. 2007, 39, 200-209. [CrossRef]

37. Cazzolla Gatti, R.; Callaghan, T.; Velichevskaya, A.; Dudko, A.; Fabbio, L.; Battipaglia, G.; Liang, J. Accelerating upward treeline shift in the Altai Mountains under last-century climate change. Sci. Rep. 2019, 9, 7678. [CrossRef] [PubMed]

38. Jump, A.S.; Mátyás, C.S.; Peñuelas, J. The altitude-for-latitude disparity in the range retractions of woody species. Trends Ecol. Evol. 2009, 24, 694-701. [CrossRef] [PubMed] 